\title{
Penerapan Ticketing OJRS+ Berbasis Online Untuk Kebutuhan Batal Tambah Perkuliahan Mahasiswa
}

\author{
Hani Dewi Ariessanti ${ }^{1}$ \\ Khanna Tiara ${ }^{2}$ \\ Siti Ela Rohilah $\mathrm{MI}^{3}$ \\ Jl. Jendral Sudirman No. 40, Modernland, Tangerang

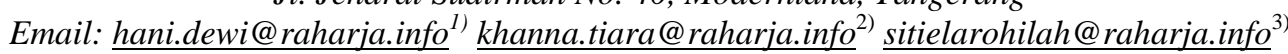

\begin{abstract}
ABSTRAK
Penjadwalan adalah salah satu masalah yang telah banyak dilakukan dalam penelitian selama bertahun-tahun. Masalah penyusunan jadwal di perguruan tinggi adalah seputar penjadwalan kuliah. Proses penentuan waktu harus dilakukan untuk setiap semester, yang merupakan tugas yang melelahkan dan memakan waktu. Alokasi keseluruhan kejadian di timeslots dan ruang dilakukan oleh proses penentuan penjadwalan kuliah dengan mempertimbangkan daftar hard constraint dan soft constraint yang disajikan dalam satu semester, sehingga tidak ada konflik yang tercipta dalam mengalokasi jadwal tersebut. Oleh karena itu, perlu dibuat sebuah aplikasi penjadwalan perkuliahan yang mampu memudahkan dan mampu menanggulangi permasalahan dalam pengaturan jadwal perkuliahan. Rancangan sistem penjadwalan perkuliahan yang diusulkan dalam penelitian ini bertujuan untuk mengoptimalkan penyusunan jadwal perkuliahan menggunakan metode Auto Generate Timetable yang sudah ada sebelumnya untuk mencari kandidat terbaik penjadwalan kuliah dengan tujuan meminimalisir konflik dan mengoptimalkan penyusunan jadwal. Hasil akhir dari proses generate adalah terbentuknya jadwal kuliah dimana jadwal yang tercipta masih membutuhkan proses batal tambah mata kuliah. Proses batal tambah secara bersamaan ini membebani resource bandwidth dan server sehingga terjadi keterlambatan proses. Untuk itu di dalam penelitian ini diusulkan menggunakan sistem ticketing dengan QRCode Dengan adanya sistem ticketing menggunakan QRCode ini diharapkan dapat mengatasi permasalahan seputar batal tambah pada penyusunan jadwal perkuliahan.
\end{abstract}

Kata kunci: Ticketing, OJRS+, Ticketing, Auto Generate Timetable, Array, Timeslots

\begin{abstract}
Scheduling is one of the many problems that have been done in research over the years. The problem of arranging a schedule in college is about scheduling lectures. The timing process should be done for each semester, which is a tiring and time-consuming task. The overall allocation of events in timeslots and spaces is done by the process of determining lecture scheduling by considering the hard constraint and soft constraint lists presented in one semester, so no conflicts are created in allocating the schedule. Therefore, it is necessary to make a lecture scheduling application that is able to facilitate and be able to overcome the problems in arranging lecture schedule. The design of the lecturing scheduling system proposed in this study aims to optimize the preparation of lecture schedules using the existing Auto Generate Timetable method to find the best candidate scheduling lecture with the goal of minimizing conflicts and optimizing the preparation of the schedule. The end result of the generating process is the formation of the schedule of the lecture where the schedule is created still require the process of canceling plus the course. This process of simultaneously adding simultaneously loads the bandwidth and server resources resulting in process delays. For that in this study proposed using ticketing system with QRCode With the ticketing system using
\end{abstract}


QRCode is expected to overcome the problems surrounding the added plus on the preparation of lecture schedules.

Keywords: Ticketing, OJRS +, Ticketing, Auto Generate Timetable, Array, Timeslots

\section{PENDAHULUAN}

Seiring dengan perkembangan teknologi yang berkembang sangat pesat membuat sebuah sistem informasi sangat dibutuhkan. Dengan adanya teknologi informasi dan komunikasi dapat memudahkan kita untuk belajar dan mendapatkan informasi yang kita butuhkan dari mana saja, kapan saja, dan dari siapa saja. Dalam dunia pendidikan perkembangan teknologi informasi dirasa mempunyai dampak yang positif karena dengan perkembangannya teknologi informasi dunia pendidikan mulai memperlihatkan perubahan yang cukup signifikan. Banyak hal yang dirasa berbeda dan berubah dibandingkan dengan cara yang berkembang sebelumnya. Saat sekarang ini jarak dan waktu bukanlah sebagai masalah yang berarti untuk mendapatkan ilmu, berbagai fitur dan aplikasi tercipta untuk memfasilitasinya.

OJRS (Online Jadwal Rencana Studi) merupakan suatu sistem informasi yg berada didalam komponen SIS (Student Information System) yang memiliki peran untuk melakukan proses persiapan kuliah pada Perguruan Tinggi Raharja. Selain itu OJRS juga berperan dalam melakukan generate seluruh kelas yang dibuka per semester, generate KST (Kartu Studi Tetap) seluruh mahasiswa, generate jadwal mengajar seluruh dosen, serta memastikan seluruh proses batal tambah berjalan dengan baik dan lancar. Fungsi OJRS sendiri adalah suatu bentuk pelayanan kampus yang digunakan untuk melakukan batal tambah mata kuliah bagi mahasiswa yang telah melakukan pembayaran registrasi semester serta mencetak form-form yang ada didalam menu OJRS.

Saat ini Perguruan Tinggi Raharja membutuhkan suatu sistem yang mudah digunakan untuk melakukan batal tambah, maka dari itu dapat digunakan sebuah sistem Online Jadwal Rencana Studi Plus (OJRS+). OJRS+ tersebut nantinya diharapkan menjadi jalan keluar dalam hal metode batal tambah mata kuliah. OJRS+ adalah sebuah sistem untuk melayani mahasiswa dalam mengatur jadwal perkuliahan yang berbasiskan web online yang merupakan pengembangan dari sistem OJRS (Online Jadwal Rencana Studi). OJRS + merupakan sistem pelayanan kampus berbasis online yang berada didalam komponen SiS+ (Students iLearning Services) yg berfungsi untuk melakukan batal tambah jadwal perkuliahan sampai dengan mendapatkan KSTF (Kartu Study Tetap Final) dan sistem ini juga dapat diakses kapan saja, dimana saja dan dapat diakses dengan koneksi luar kampus atau menggunakan koneksi internet. ${ }^{\text {(Menurut Khanna Tiara : 2015]) }}$

Permasalahan dalam batal tambah yang berjalan saat ini adalah OJRS hanya bisa diakses di lingkungan kampus dengan menggunakan Box SIS, pada saat melakukan Swipe Card PRC (Pribadi Raharja Card) sering tidak tedeteksi dengan baik sehingga mahasiswa harus melakukannya secara berulang kali, sering terjadi error serta loading kecepatan akses data yang lama sehingga dapat memakan waktu dan menimbulkan antrian mahasiswa yang akan melakukan batal tambah jadwal kuliah. Karena sistem batal tambah yang digunakan kurang efektif untuk mahasiswa maka digunakan sistem OJRS+. Dengan adanya OJRS+ diharapkan bisa memberikan kemudahan bagi setiap mahasiswa Perguruan Tinggi Raharja dalam melakukan batal tambah mata kuliah yang Vol.3 No.2 - Agustus 2017 
bisa dilakukan dimana saja dan kapan saja hanya dengan koneksi intenet. Pada penelitian ini pembahasan difokuskan pada ticketing penjadwalan mata kuliah di perguruan tinggi Raharja. Ticket OJRS+ merupakan sebuah gagasan baru yang ada pada bagian dari OJRS+ sebelum melakukan batal tambah mata kuliah diciptakan oleh Perguruan Tinggi Raharja. Ticket OJRS+ ini di khususkan untuk mahasiswa yang ingin melakukan batal tambah secara online pada OJRS+. Fungsi dari Ticket OJRS+ adalah sebuah ticket yang digunakan sebagai pintu masuk untuk melakukan batal tambah pada OJRS+ dan selain itu agar mahasiswa mengetahui kapan jadwal mahasiswa tersebut melakukan batal tambah mulai dari tanggal dan waktu di bukanya pengaturan jadwal. Ticket OJRS+ dibuat pada halaman SiS+ tepatnya pada button yang terletak di bawah foto.

\section{PERMASALAHAN}

Untuk prosedur sistem yang berjalan saat ini pada proses batal tambah mata kuliah yang berada di Perguruan Tinggi Raharja masih manual dirasa masih banyak kekurangan dan kendala yang dihadapi. Dimana mahasiswa melakukan pengisian form isian Kartu Rencana Studi (KRS) secara manual dan penyusunan Jadwal Rencana Studi (JRS) dilakukan melalui rapat jurusan selama beberapa bulan, pengolahan data dilakukan secara manual menggunakan program excel untuk menganalisa mata kuliah apa saja yang harus dibuka dan berapa jumlah kelas yang harus dibuka, membuat tabel JRS dan mengatur jadwal dosen menggunakan excel tersebut. Data JRS tersebut kemudian dilakukan input ke program MS Access, sehingga petugas Registrasi Perkuliahan dan Ujian (RPU) dapat mengentri isian KRS ke dalam sistem access dan melakukan proses batal tambah mahasiswa dan selanjutnya dapat mencetak Kartu Studi Tetap Final (KSTF) mahasiswa. Permasalahan pada sistem ini adalah pengolahan data tidak akurat, lamanya proses pembuatan JRS yang memakan waktu beberapa bulan, terlambatnya pencetakan KSTF, terjadinya kesalahan input oleh petugas, adanya antrian batal tambah di loket RPU yang sangat panjang selama beberapa minggu serta tidak tertibnya pelaksanaan batal tambah mahasiswa. Program access yang digunakan untuk proses batal tambah juga mengalami kendala karena sistem tersebut harus di share kepada beberapa komputer petugas RPU selama berjalannya proses batal tambah, database yang digunakan tidak memungkinkan dilakukan untuk pengolahan data yang demikian besar dan mobilitasnya sangat tinggi, sehingga menyebabkan sistem sering mengalami error, serta adanya protes dari mahasiswa karena pelayanan batal tambah yang tidak memuaskan. 


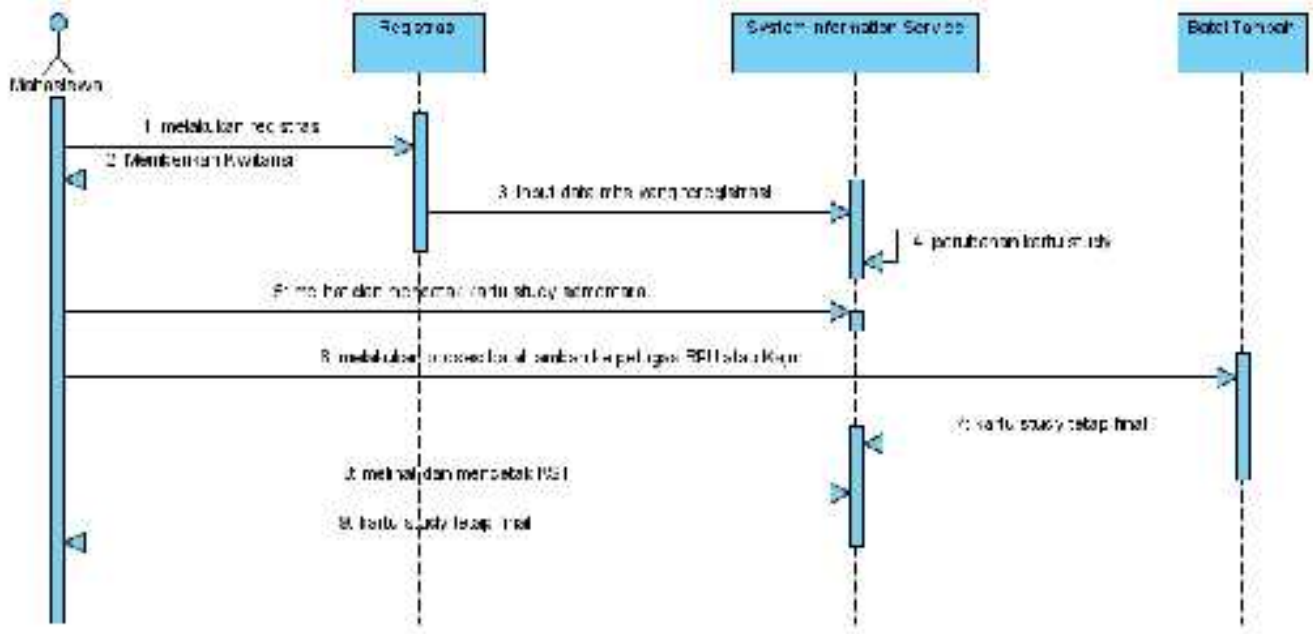

Gambar 2. Sequence Diagram

Berdasarkan gambar 2 Sequence Diagram yang menggambarkan tahapan dari sistem OJRS yang berjalan terdapat 1 actor yang melakukan kegiatan, 9 message yang menggambarkan urutan proses pada OJRS. untuk deskripsi dari sequence diagram adalah sebagai berikut :

Mahasiswa sebagai actor yang melakukan kegiatan. Mahasiswa melakukan registrasi, memberikan kwitansi kepada kasir, input data mahasiswa yang telah melakukan registrasi menggunakan PRC, kemudian pada SIS terdapat informasi perubahan kartu studi, dan melakukan proses batal tambah ke petugas RPU, mendapatkan kartu studi tetap final, melihat kemudian mencetak KSTF. lalu mendapatkan KSTF (kartu studi tetap final)

Tidak efektifnya pelayanan tersebut merugikan mahasiswa karena harus datang kekampus dan mengisi saldo PRC untuk mencetak KSTF, selain itu pemborosan dalam penggunaan kertas.

Permasalahan lainnya adalah koneksi sering terputus-putus dan lambatnya akses Box SIS, sering juga terjadi server down sewaktu-waktu, jaringan tidak terkoneksi atau RTO (Request Time Out). Beberapa kali terjadi kerusakan pada modul hardisk server untuk itu data harus di recovery dan ini banyak merugikan manajemen karena sebagai aset yang tidak ternilai harganya. Terdapat juga UPS yang rusak sehingga mengganggu kinerja server, hardware komputer client yang sudah lama penggunaannya juga menyebabkan lama waktu akses data. Selain itu terbatasnya sumber daya manusia yang memiliki spesialisasi dalam pemeliharaan server. Ruangan server juga harus dilengkapi dengan pendingin ruangan yang harus nyala selama 24 (dua puluh empat) jam non stop ini juga berakibat bertambahnya biaya operasional. Jika PRC Mahasiswa tersebut rusak atau hilang mahasiswa tidak bisa mengakses OJRS. Selain itu sistem ini memiliki permasalahan pada keamanan serta permasalahan lainnya.

Maka rumusan dari penelitian ini adalah bagaimana mengembangkan penjadwalan kuliah dengan auto generate timetable dengan array untuk pembentukan jadwal kuliah dan mengembangkan sistem batal tambah mata kuliah menggunakan ticketing OJRS+. Berdasarkan rumusan masalah yang telah di identifikasi maka tujuan yang ingin dihasilkan adalah menciptakan sistem yang dapat mengelola data jumlah mahasiwa 
yang melakukan batal tambah, menciptakan sebuah sistem yang mampu mengontrol status registrasi mahasiswa, menciptakan suatu sistem yang mampu membantu dalam penyusunan jadwal mata kuliah dan bagaimana membuat sistem ticketing OJRS+ menjadi lebih fleksibel dan bermanfaat bagi pengguna dan OJRS+ itu sendiri. Sehingga dapat memberikan pelayanan terbaik untuk para pengguna dan tentunya mempermudah dalam melakukan batal tambah perkuliahan.

\section{LITERATURE REVIEW}

Literature Review adalah "Literature Review is a critical analysis of the research conducted on a particular topic or question in the field of science" yang artinya Literature Review merupakan analisa kritis dari penelitian yang sedang dilakukan terhadap topik khusus atau berupa pertanyaan terhadap suatu bagian dari keilmuan. Literature Review membantu kita dalam menyusun kerangka berfikir yang sesuai dengan teori, temuan, maupun hasil penelitian sebelumnya dalam menyelesaikan rumusan masalah pada penelitian yang kita buat. ([Menurut Yudi Agusta : 2007]) banyak peneliti yang sebelumnya melakukan penelitiannya tentang penjadwalan mata kuliah dan OJRS+. Dalam upaya pembuatan Ticketing OJRS+ ini perlu dilakukan studi pustaka untuk dijadikan sebagai bahan acuan untuk memperkuat hasil penelitian dengan cara mengindentifikasikan metode yang pernah dilakukan, mengembangkan penelitian sebelumnya yang memiliki korelasi yang seimbang dengan sistem OJRS+. Beberapa literature review yang didapakan diantaranya adalah sebagai berikut :

1. Penelitian yang dilakukan oleh Untung Rahardja, Khanna Tiara, dan Ray Indra Taufik Wijaya dengan judul "Penerapan Rinfo Sebagai Media Pendukung Untuk Proses Pembelajaran Pada Perguruan Tinggi Raharja". Dari hasil penelitian ini menunjukkan bahwa Rinfo ini adalah Gmail, yang di adaptasi dari Google Platform dengan ciri khas raharja.info sebagai domainnya. Rinfo ini adalah media komunikasi sekaliguas alat pendukung dalam prses pembelajaran di Perguruan Tinggi Raharja. Karena selain terintegrasi dengan TPi, Rinfo ini pun terhubung pula dengan alat penunjang pembelajaran lainnya, seperti Docs, Drive, Sites dan alat penunjang lainnya. ${ }^{(1)}$

2. Penelitian yang dilakukan oleh Fitria Affani pada tahun 2013 dengan judul "Kualitas Pelayanan Kartu Rencana Studi (KRS) Online Di Fakultas Ilmu Sosial dan Ilmu Politik Universitas Sriwijaya". Penelitian ini bertujuan untuk mengetahui kualitas pelayanan kartu rencana studi online dengan membandingkan antara pelayanan yang yang dirasakan (perceived service) dengan pelayanan yang diharapkan (Expected service) dengan menggunakan 5 dimensi kualitas pelayanan. Penelitian ini merupakan penelitian deskriptif kuantitatif menggunakan desain penelitian survei dengan menggunakan teknik pengolahan kuisioner sebagai instrument penelitian yang ditujukan kepada mahasiswa sosiologi angkatan 2008 sebagai responden. Lokasi penelitian berada di Fakultas Ilmu Sosial dan Ilmu Politik Universitas Sriwijaya. Unit analisis pada penelitian ini adalah individu yang aktif berkuliah di jurusan sosiologi fisip unsri angkatan 2008. Penarikan sampel dengan menggunakan sampling jenuh karena jumlah populasi relatif kecil. Proses analisis data dilakukan melalui empat tahapan yaitu pengujian validitas dengan mengunakan rumus korelasi product moment dan reliabilitas data dengan mengunakan rumus 
Sperman Brown, pengujian normalitas data dengan menggunakan Chi Squere, dan pengujian hipotesis dengan mengunakan uji perbandingan antara harapan dan kinerja yang dirasakan responden di lapangan, dikarenakan data dinyatakan tidak normal, maka jenis statistik yang digunakan adalah statistik nonparametrik. Hasil penelitian ini adalah kualitas pelayanan Kartu Rencana Studi (KRS) online di fakultas ilmu sosial dan ilmu politik universitas sriwijaya adalah tidak baik karena harapan mahasiswa lebih besar dari pelayanan yang dirasakan di lapangan (kenyataan). ${ }^{(2)}$

3. Penelitian yang dilakukan oleh Ali Ibrahim pada tahun 2011 dengan judul "Pengembangan Sistem Monitoring Tugas Akhir Berbasis Short Message Service (SMS) Gateway Di Fasilkom Unsri”. Dalam penelitian ini menghasilkan suatu sistem yang memberikan layanan khusus kepada mahasiswa, dosen, administrasi jurusan dan ketua jurusan. Dengan sistem ini akan membentuk komunikasi interaktif, sehingga proses layanan informasi menjadi lebih mudah, cepat, efesien dan efektif. Penelitian ini juga didukung dengan semakin pesatnya perkembangan penggunaan telepon seluler dikalangan mahasiswa. Sehingga dapat menghasilkan suatu aplikasi atau perangkat lunak yang dapat membantu administrasi jurusan seperti : (1) memberikan status proposal tugas akhir mahasiswa, (2) memberikan informasi jadwal seminar kepada mahasiswa, (3) mengingatkan mahasiswa yang proposalnya sudah di terima tapi belum di proses. Selain itu dosen pembimbing dapat mengingatkan atau menginformasikan kepada mahasiswa bimbingannya agar segera untuk menyelesaikan tugas akhir, memotivasi dan memberi support kepada mahasiswa. Kelebihan yang lain pada sistem yang akan dibuat adalah dapat mengirimkan SMS balasan atau request status proposal mahasiswa, mengirimkan SMS jadwal ujian tugas akhir, mengirimkan SMS early message kepada mahasiswa, dosen pembimbing, dosen penguji bahwa ujian akan dimulai satu jam lagi, mengirimkan SMS nilai ujian akhir mahasiswa. ${ }^{(3)}$

4. Penelitian yang dilakukan oleh Joko Tryono pada tahun 2010 dengan judul "Pelayanan KRS Online Berbasis SMS". Hasil dari konsep informasi yang dibuat ini adalah: (1) Waktu proses informasi layanan ini dapat berlangsung secara singkat, cepat dan akurat dengan rata-rata membutuhkan waktu proses secara keseluruhan berkisar 3 s/d 3.5 detik per sekali mengirimkan sms. (2) Keamanan dan akurasi data dapat dipertanggung jawabkan, karena pengisian KRS hanya bisa dilakukan oleh nomor hp yang telah terdaftar dan terikat dengan nomor mahasiswa sebagai user utama. (3) Dapat menggunakan SIM Card yang berbeda, baik dari sisi Server maupun Klien. (4) Hampir semua daerah di Indonesia telah terjangkau oleh jaringan telpon baik itu GSM, CDMA atau lainnya, sehingga model SMS ini lebih mudah untuk diaplikasikan. (5) Data yang dikirimkan ke DBMS akan diproses oleh trigger yang digunakan sebagai jantung utama sistem ini, yang menjadikan script programming hampir tidak dominan. ${ }^{(4)}$

5. Penelitian yang dilakukan oleh Irfrans Kusmana, Luh Kesuma Wardhani, dan Muhammad Safrizal dengan judul "APLIKASI PENJADWALAN MATA KULIAH MENGGUNAKAN ALGORITMA PARTICLE SWARM OPTIMIZATION (PSO)". Hasil dari penelitian adalah untuk membangun aplikasi penjadwalan kuliah menggunakan algoritma ParticleÂ Swarm Optimization $\hat{A}$ (PSO). Algoritma $\hat{A}$ ini dipilih $\hat{A}$ sebagai $\hat{A}$ algoritma yang digunakan dalam penelitian $\hat{A}$ ini karena $\hat{A}$ algoritma Â PSO Â yang Â merupakan $\hat{A}$ algoritma Â heuristik, Â adalah $\hat{A}$ salah $\hat{A}$ 
satu $\hat{A}$ metode $\hat{A}$ optimasi $\hat{A}$ yang $\hat{A}$ menggabungkanÂ localsearch dan global search. Algoritma ini dapat memecahkan masalah dengan membentuk partikelpartikel padaÂ populasi awal secara acak, mengevaluasi nilai Â fitness, dan mengupdate velocity serta posisi dari partikel. Dengan $\hat{A}$ demikian diharapkan output yang dihasilkan merupakan kombinasi $\hat{A}$ terbaik dari serangkaian komponen yang ada.Â Kasus penjadwalan yang digunakan pada penelitian ini adalah penjadwalan mata kuliah di UIN Sultan Syarif KasimÂ Riau (UIN SUSKA). Permasalahan yang terjadi pada penjadwalan mata kuliah di UIN SUSKA Riau adalah tidak $\hat{A}$ optimalnya pemenuhan beberapa contraint seperti keterbatasan ruangan. Dari hasil pengujian, aplikasi penjadwalan $\hat{A}$ perkuliahan meggunakan algoritma PSO mampu menghasilkan $\hat{A}$ jadwal perkuliahan yang $\hat{A}$ sudah $\hat{A}$ tidak ada bentrok $\hat{A}$ tetapi masih tidak memenuhi dari segi kualitas yaitu jam dimulainya perkuliahan inti yang difokuskan pada jam-jam $\hat{A}$ yang efektif. ${ }^{(5)}$

6. Penelitian yang dilakukan oleh Moh. Iqbal Awi Makaram pada tahun 2013 dengan judul "Pengembangan Sistem Informasi Online Jadwal Rencana Study (OJRS+) Pada Perguruan Tinggi Raharja Dengan Metode AGTTA (Auto Generate Time Table With Array) Menggunakan Yii Framework".Berdasarkan analisa yang dilakukan oleh penulis dan masalah - masalah yang dihadapi dalam penyusunan jadwal rencana study sering terjadi bentrok jadwal yang dibuat copy paste dari jadwal sebelumnya hanya kode kelas saja yang dirubah namanya, sehingga banyak ruang - ruang kosong yang tidak digunakan. Perangkat lunak OJRS+ (Online Jadwal rencana Study) merupakan sebuah sistem berbasis web yang dibuat menggunakan metode Auto Generate Time Table With Array (AGTTA), Yii Framework dan menggunakan bahasa pemrograman PHP. Database Management System (DBMS) yang digunakan adalah MySQL dan metode penelitian menggunakan Waterfall Model. Sistem informasi ini akan mempermudah mahasiswa dalam melakukan penyusunan jadwal rencana study tanpa harus mengantri lama di Box SIS. (Moh. Iqbal Awi Makaram 2013). ${ }^{(6)}$

7. Penelitian yang dilakukan oleh Behrooz Gharleghi dan Benjamin Chan Yin pada tahun 2014 dengan judul "Electronic Ticketing in Airlines Industries among Malaysians : the determinants" investigate the determinants of the usage of online ticketing within airline industry among consumers in in malaysia. Data for this study was collected through self-administrated questionaire and distributed through through convenient sampling method. A total of 200 completed and usable questionnaires have been collected. Pearson Correlation analysis and ANOVA table were tested to determine the interrelation of different variables in electronic ticketing usage. Findings of this study are limited by the number of respondents, area and location of the study, and absence of other methods to obtain results other than secondary research and questionnaire. Empirical results show that there is a significant correlation between payment method, corporate image, security, and web design with usage of electronic ticketing. This study is important to the marketers to understand the online ticketing usage in airline industry. Marketers could also make improvement and strengthen the marketing strategy based on selected variable to be more competitive. ${ }^{(7)}$

8. Penelitian yang dilakukan oleh pada tahun 2016 dengan judul "A Novel Technique for Jobs Scheduling In Cloud Computing Systems" It is characterized as mainly rely on the Internet to provide services for organizations and consumers and to take 
advantage of resource sharing, in addition to that it is associated with many of the central remote servers to maintain user data, so it has become an effective way that will allow the world to use the many kind of applications without making an effort to be downloaded. Manyjob scheduling algorithms have been proposed to achieve both customer satisfaction and high resource utilization. However, better algorithms to achieve these goals efficiently are still needed. This paper proposes a hybrid technique for jobs scheduling based on Neural Network (NN) algorithm. The proposed algorithm classifies the jobs into four different classes. Furthermore, a Heuristic Resource Borrowing Scheme (HRBS) sproposed to exploit all services which has offered by cloud computing. Simulation is conducted using extensive (Cloud-Sim) simulator to measure the efficiency of the suggested algorithm in terms of average throughput, average turnaround time and average of context switch. The obtained results show that the proposed scheme outperforms other state of the art scheduling schemes. ${ }^{(8)}$

9. Penelitian yang dilakukan oleh Jefri Gumilar Pratama, Afriyudi, dan Ilman Zuhri Yadi pada tahun 2012 dengan judul "Analisa Sistem Informasi Entri Krs Online Pada Universitas Bina Darma Dengan Menggunakan Metode End-User Computing (Euc) Satisfaction". Dari hasi penelitian ini menunjukan bahwa dilihat dari faktor isi perlu ditambahkan link untuk men-download panduan untuk pengentrian KRS. Karena fasilitas ini belum terlihat pada sistem informasi entri KRS online. Sebab, mahasiswa yang masih awam dalam menggunakan sistem inidikhawatirkan akan mengalami kesulitan dalam melakukan pengentrian. Dari faktor bentuk, pada frame masih perlu ditambahkan field untuk melihat jadwal mata kuliah, agar mahasiswa dapat melihat lebih detail jadwal mata kuliah yang diambilnya dan perlu ditambahkan gambar atau animasi agar bentuk dari sistem ini dapat lebih menarik. Serta pada setiap form menu perlu ditambahkan deskripsi agar mahasiswa mengerti fungsi-fungsi dari setiap form. Dari sisi akurasi, keakuratan dari sistem informasi entri KRS online sudah cukup baik, tetapi akan lebih baik lagi jika apabila ditambahkan informasi mengenai dosen yang mengajar mata kuliah tersebut dan yang mata kuliah pilihan atau mata kuliah wajib. Dari sisi kemudahan, perlunya penyuluhan terhadap penggunaan sistem informasi entri KRS online. Dan juga dikarenakan jumlah mahasiswa UBD yang sangat banyak, jadi pada saat mahasiswa melakukan entri KRS secara serentak akan memakan banyak bandwitch, jadi harus dilakukan penambahan bandwitch guna mengatasi hal tersebut. Dan juga agar mahasiswa lebih mudah dalam melakukan pengentrian, proses pengentrian diharapkan dapat dilakukan bukan hanya melalui jaringan intranet, melainkan jaringan internet yang dapat diakses dari mana saja. Dari ketepatan waktu, sistem informasi entri KRS online alangkah baiknya jika proses pengentrian dapat dilakukan melalui jaringan internet, jadi apabila mahasiswa yang sedang berada diluar daerah ingin melakukan pengentrian KRS, tidak perlu lagi repot-repot harus datang ke UBD untuk mengentri, cukup melalui warnet atau menggunakan modem atau melalui hotspot dimana saja, asalkan belum lewat batas waktu untuk mengentri. (Jefri Gumilar Pratama, Afriyudi, dan Ilman Zuhri Yadi 2012). ${ }^{(9)}$

10. Penelitian yang dilakukan oleh Zhen Song, Hekan Schunnesson, Mikael dan Rinne John Sturgul pada tahun 2015 dengan judul "Intelligent Scheduling for Underground Mobile Mining Equipment" Many studies have been carried out and many commercial software applications have been developed to improve the 
performances of surface mining operations, especially for the loader-trucks cycle of surface mining. However, there have been quite few studies aim-ing to improve the mining process of underground mines. In underground mines, mobile mining equipment is mostly scheduled instinctively, without theoretical support for these decisions. Furthermore, in case of unexpected events, it is hard for miners to rapidly find solutions to reschedule and to adapt the changes. This investigation first introduces the motivation, the technical background, and then the objective of the study. A decision support instrument (i.e. schedule optimizer for mobile mining equipment) is proposed and described to address this issue. The method and related algorithms which are used in this instrument are presented and discussed. The proposed method was tested by using a real case of Kittilä mine located in Finland. The result suggests that the proposed method can considerably improve the working efficiency and reduce the working time of the underground mine. ${ }^{(10)}$

Dari 10 (sepuluh) literature review yang ada, telah banyak penelitian mengenai metode Pengisian KRS (Kartu Rencana Studi) berbasis online. Pemanfaatan (Short Message Service) SMS Gateway sebagai monitoring Tugas Akhir, serta aplikasi penjadwalan mata kuliah menggunakan Algoritma Particle Swarm Optimization (PSO). Namun dapat disimpulkan pula bahwa belum ada peneliti yang secara khusus membahas mengenai ticketing batal tambah, membebani resource bandwidth dan server. Dimana seorang mahasiswa dapat melakukan dan mengatur jadwal kuliah, menambahkan mata kuliah, membatalkan jadwal kuliah sesuai dengan pilihan jam, hari dan tanggal, hingga didapatkan output berupa KSTF (Kartu Studi Tetap Final).

\section{PEMECAHAN MASALAH}

Untuk mengatasi permasalahan diatas maka diperlukan sebuah sistem untuk mempermudah dalam melakukan batal tambah mata kuliah pada OJRS+. Dari rumusan masalah tersebut menghasilkan pemecahan masalah yaitu dengan adanya sistem ticketing OJRS+ maka diharapkan saat melakukan batal tambah dapat dilakukan secara mudah, cepat, dan tepat sasaran. Pada pemecahan masalah menggunakan Activity Diagram Crate Ticket OJRS+ :

\section{METODE PENELITIAN}

Metode penelitian ini diawal dengan melakukan identifikasi masalah, menentukan permasalahan dari sistem penjadwalan, analisa kebutuhan sistem, generate jadwal, dan membangun sistem ticketing pada sistem.

Pengambilan data dilakukan dengan metode observasi, wawancara dan studi pustaka (Literature Review) Pengambilan sampel data berdasarkan karakteristik yang ditentukan sesuai dengan masalah penelitian. Dalam hal ini data yang digunakan adalah data skunder diambil dari Perguruan Tinggi Raharja Tangerang dengan enam program studi yaitu sistem informasi, teknik informatika, sistem komputer, manajemen informatika jenjang diploma, teknik informatika jenjang diploma serta komputerisasi akuntansi. Data yang dibutuhkan adalah data resources (timeslot, mahasiswa, matakuliah, ruangan, kurikulum, nilai, status mahasiswa, shift kuliah, mahasiswa reguler dan transfer) dan data soft constraint. 


\section{PEMBAHASAN}

Activity diagram merupakan sebuah tipe dari diagram workflow yang menggambarkan tentang aktivitas dari pengguna ketika melakukan setiap kegiatan dan aliran sekuensial. ([Satzinger, 2009:64]).

Pada metode penggunaan Activity Diagram ini dapat digambarkan dengan jelas mengenai Create Ticket OJRS+. Tujuan dari ticket OJRS+ itu sendiri adalah sebagai nomor antrian atau pintu masuk untuk mengakses OJRS+.

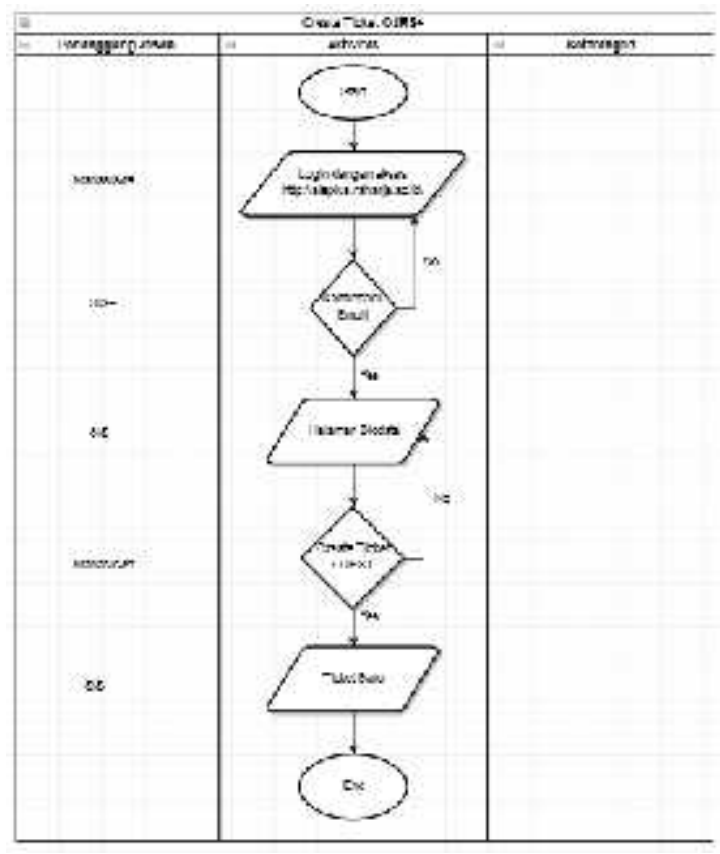

Gambar 3. Activity Diagram Create Ticket OJRS+ 


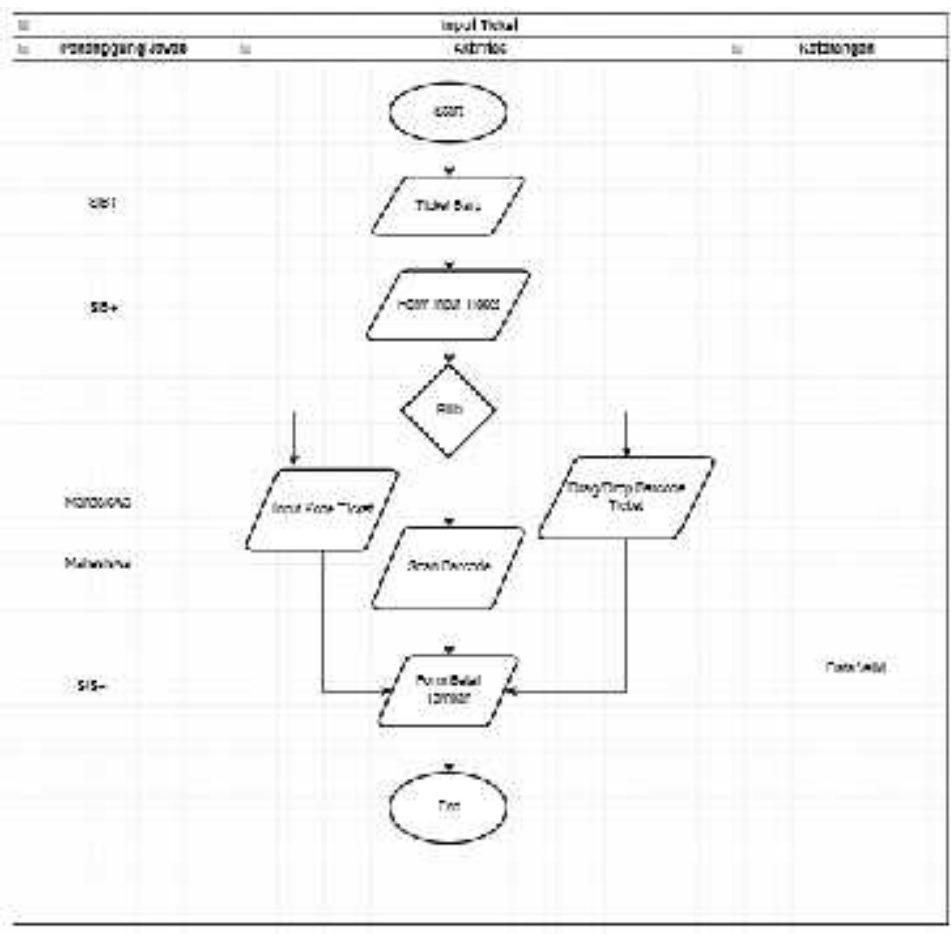

Gambar 4. Activity Diagram Input Ticket OJRS+

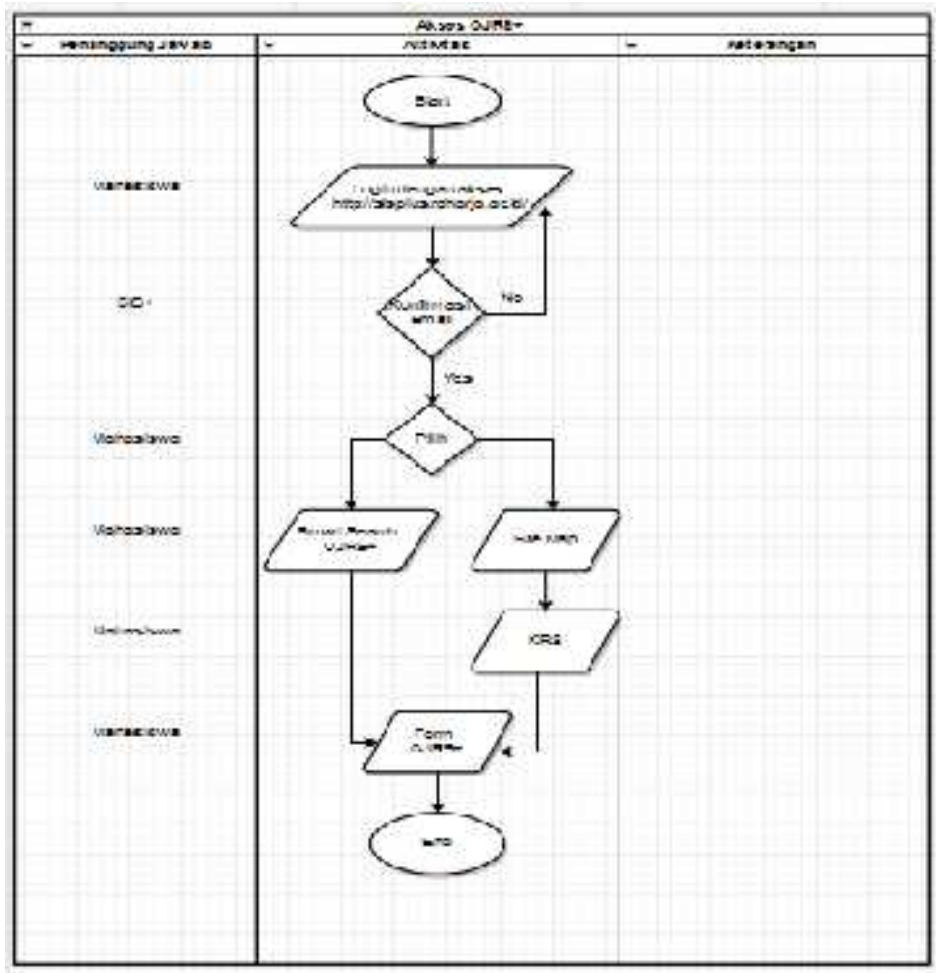

Gambar 5. Activity Diagram Rule Akses OJRS+

Dari gambar diatas, dapat dilihat bahwa dengan adanya sistem ticketing OJRS+ pada saat melakukan batal tambah mata kuliah sangat mempermudah karena pengguna hanya perlu mengcopy paste, melakukan scan barcode dan input kode ticket OJRS+. Ticket 
OJRS+ dibuat pada halaman SiS+ tepatnya pada button yang terletak di bawah foto. hal tersebut tentunya mempermudah pengguna untuk mengakses batal tambah mata kuliah pada OJRS+.

Ticket adalah suatu dokumen perjalanan yang dikeluarkan oleh suatu perusahaan yang berisi rute, tanggal, harga,data penumpang yang digunakan untuk melakukan suatu perjalanan berupa karcis kapal, pesawat terbang, dsb. (Kamus Besar Bahasa Indonesia (2001, p1191). Tentu saja dalam hal ini, ticket OJRS+ merupakan pintu masuk untuk mengakses batal tambah perkuliahan.

\section{IMPEMENTASI}

Berikut ini adalah tampilan implementasi Sistem ticketing OJRS+ (Online Jadwal Rencana Studi Plus) untuk meningkatkan kualitas pelayanan dalam pengaturan jadwal perkuliahan pada peneliti maupun pengguna. Untuk impelementasi ticketing OJRS+ dapat diakses pada link URL berikut ini : sisplus.raharja.ac.id

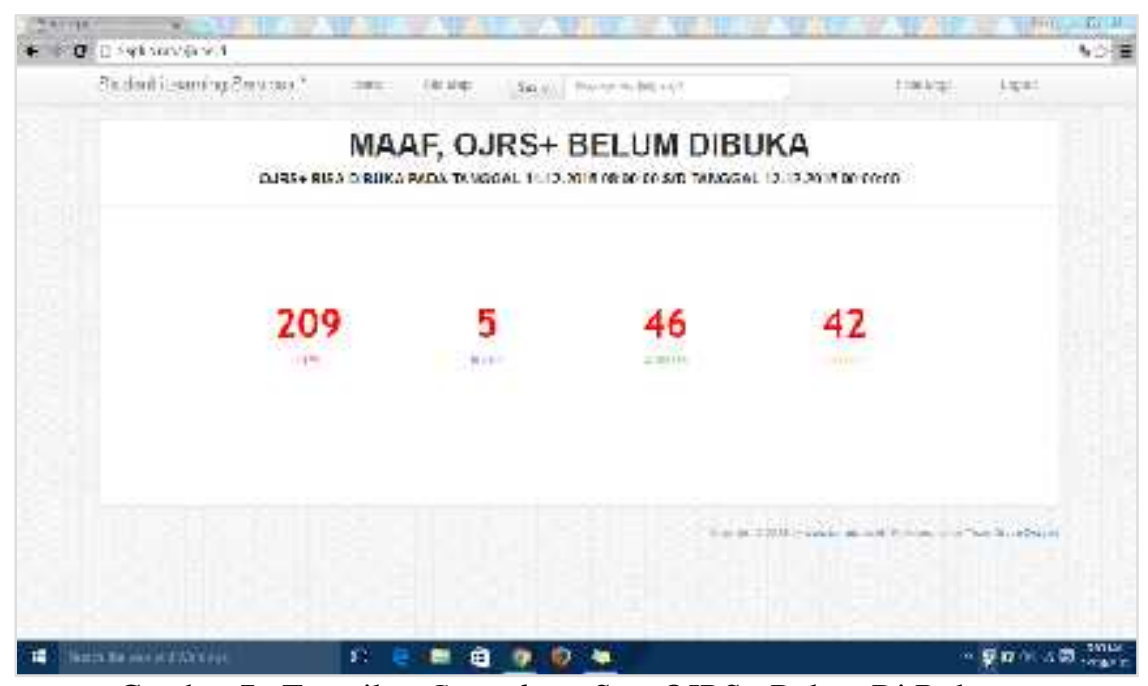

Gambar 7. Tampilan Countdown Saat OJRS+ Belum Di Buka 


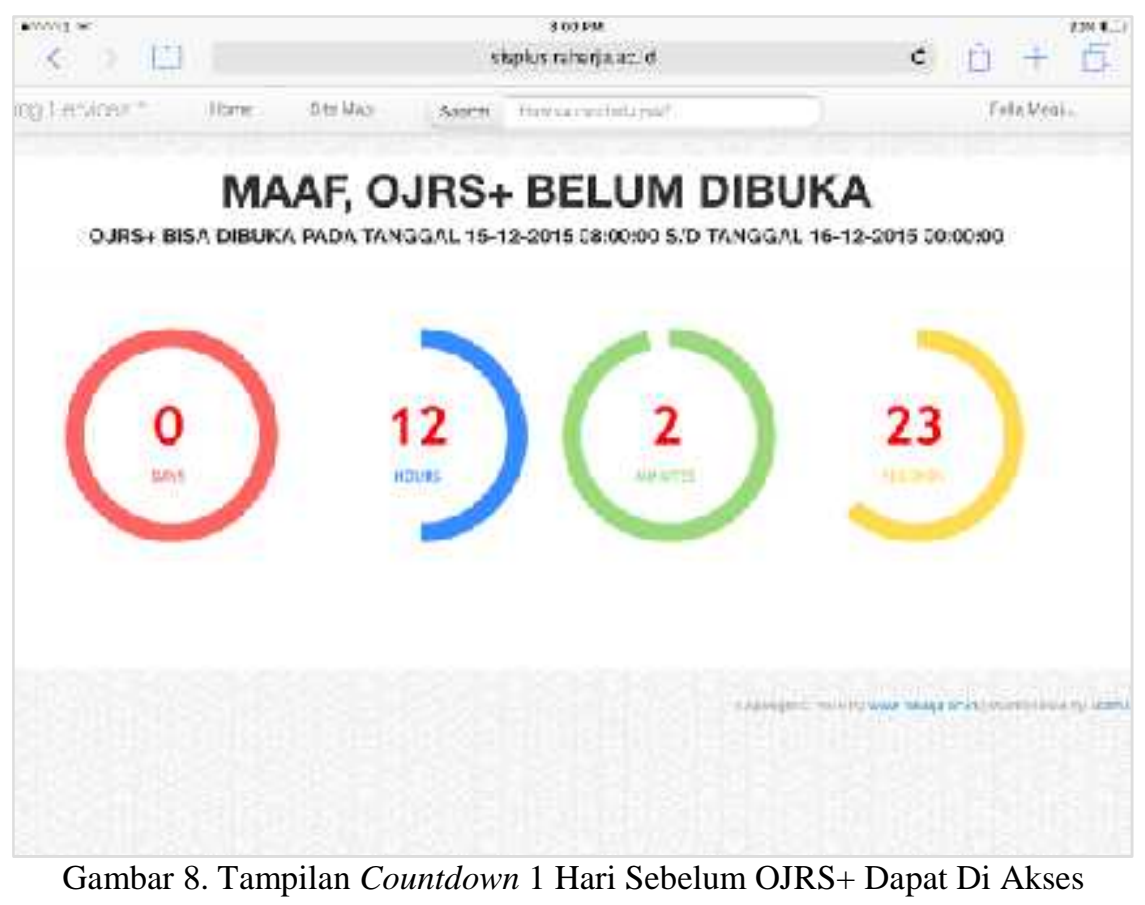

Pada gambar 7 dan 8 menjelaskan tentang Countdown OJRS+ terlihat 1 hari sebelum OJRS+ dimulai

Keterangan : Ditentukan adalah 1 hari sebelum OJRS+ dimulai terdapat countdown pada sistem OJRS+ yang menginfokan bahwa OJRS+ masih belum dapat diakses, pada countdown. Pada pelaksanaannya untuk countdown bisa diterbitkan pada 3 hari sebelum OJRS+ akan dimulai.

Setelah berhasil melakukan registrasi pada bagian Layanan Keuangan Mahasiswa, peneliti atau pembaca dapat melakukan create ticket untuk melakukan batal tambah perkuliahan.

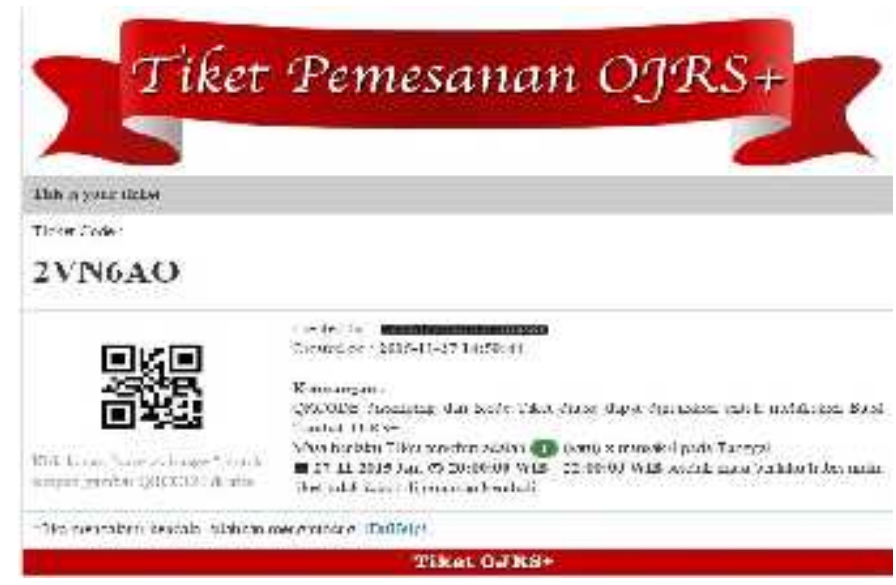

sumber : Ticket OJRS+ (2015: iran.raharja.info)

Gambar 9. Implementasi Ticketing pada OJRS+

Gambar 9 merupakan contoh dari implementasi Ticketing OJRS+ ticket dapat diinput dengan 3 cara yaitu : Input copy paste code ticket OJRS+ Foto menggunakan webcam, Upload foto QRCODE 


\section{Keterangan : \\ QRCODE disamping dan Kode Tiket diatas dapat digunakan untuk melakukan Batal Tambah OJRS+. \\ Masa berlaku Tiket tersebut adalah (1) (satu) x transaksi pada Tanggal. \\ 27-11-2015 Jam () 20:00:00 WIB - 22:00:00 WIB setelah masa berlaku habis maka tiket tidak dapat di gunakan kembali.}

Gambar 10. Notifikasi masa berlaku ticket OJRS+

Pada gambar 10 merupakan notifikasi yang berada di sebelah kanan QRCODE batal tambah OJRS+ yang memberikan keterangan bahwa ticket hanya berlaku 1 (satu) kali transaksi dan hanya berlaku untuk 1 (satu) jam. Berikut adalah Laporan Visitor Mahasiswa pada sistem batal tambah mata kuliah Perguruan Tinggi Raharja yaitu OJRS+

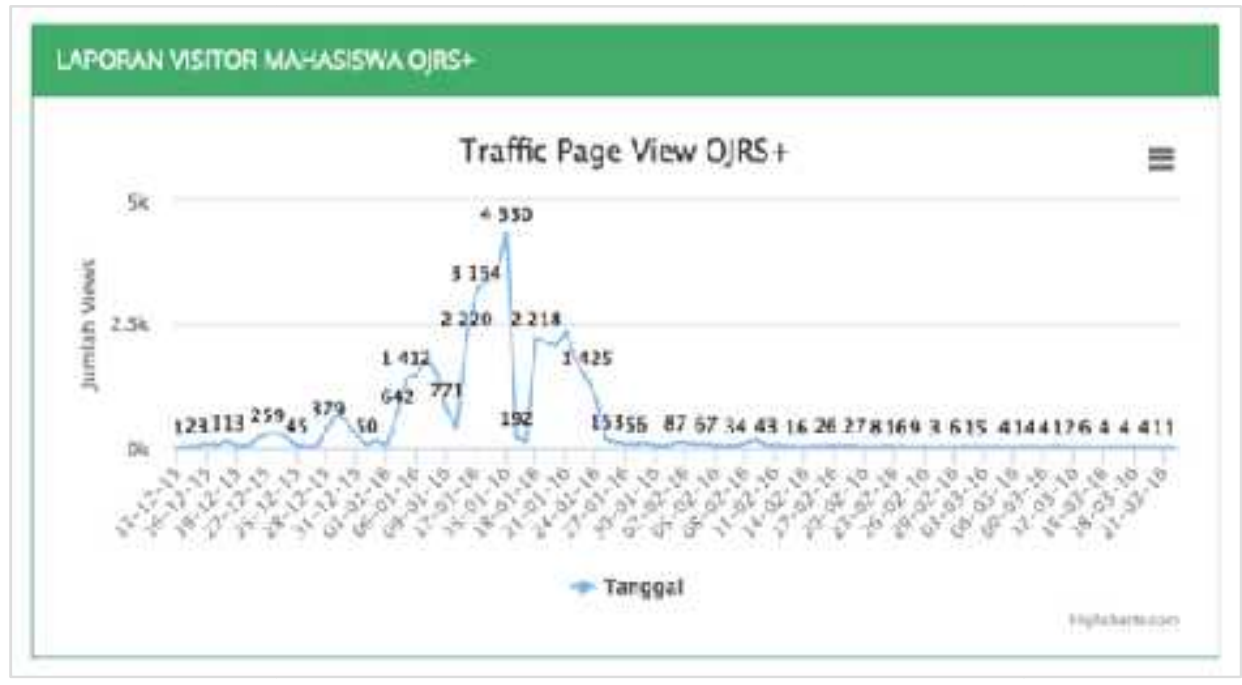

Gambar 11. Laporan Visitor Mahasiswa OJRS+

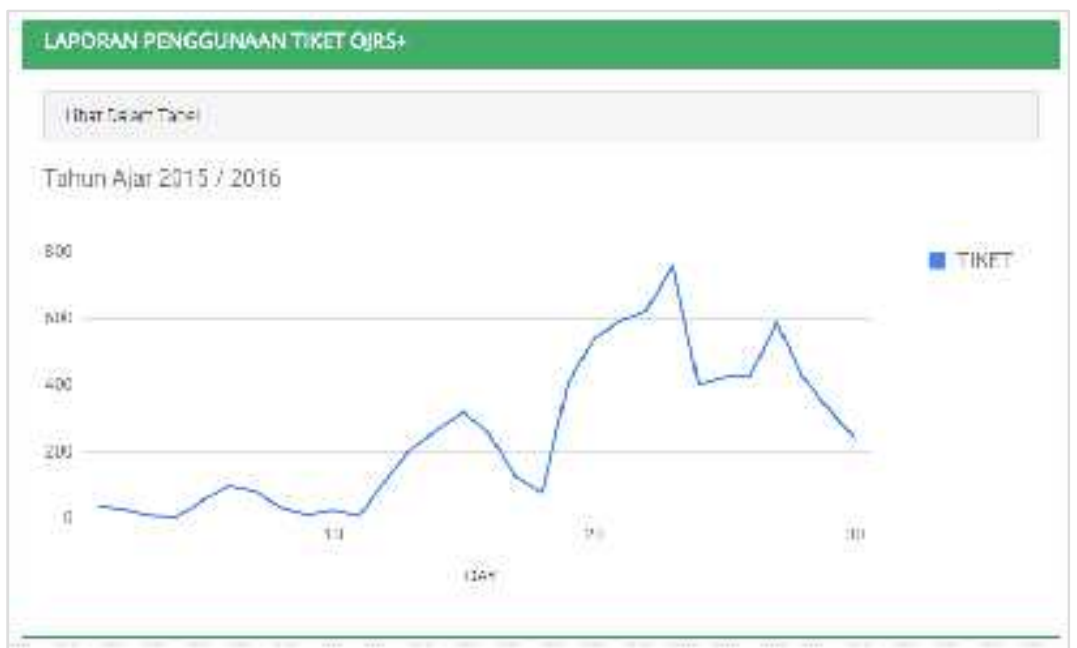


Gambar 12. Grafik Laporan Penggunaan Ticket OJRS+

Pada gambar 12 menjelaskan bahwa penggunaan ticket pada hari ke 20 (dua puluh) mengalami peningkatan dari hari sebelumnya yaitu sebanyak 800 (delapan ratus ticket). Selanjutnya pada gambar 13 rincian data laporan penggunaan Ticket OJRS+ dengan menampilkan 30 data terbaru.

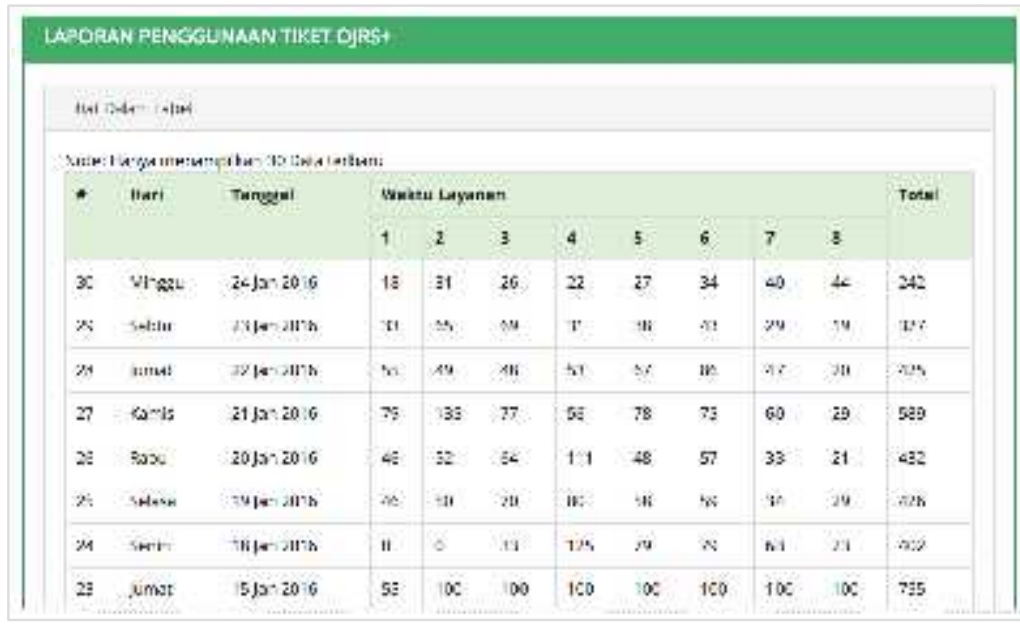

Gambar 13. Rincian Data Laporan Penggunaan Ticket OJRS+

Pada gambar 11 merupakan rincian data laporan pengguna Ticket OJRS+ yang ditampilkan hanya 30 data terbaru saja. Yang berisi hari, tanggal, waktu layanan dan total dari penggunaan ticket setiap harinya.

\section{KELEBIHAN PENERAPAN TICKETING OJRS+}

Sistem ticketing OJRS+ berbasis web dapat menyediakan data dan pengolahan data untuk segala informasi mengenai jadwal mata kuliah, melayani kebutuhan batal tambah perkuliahan mahasiswa secara online, informasi KST (Kartu Studi Tetap) dan KSTF (Kartu Studi Tetap Final). Ticketing juga berfungsi sebagai penomoran atau antrian untuk melakukan jadwal rencana studi secara online, setelah melakukan registrasi peneliti atau pembaca bisa langsung melakukan pengaturan jadwal rencana studi tanpa harus antripada Box SiS atau RPU. Hal ini tentunya lebih fleksibel karena ticket OJRS+ hanya perlu copy paste atau scan $Q R$ code saat terjadi ticket unregistered. Selain itu dalam sehari peneliti atau pengguna dapat mengcreate ticket beberapa kali dalam sehari tentunya dengan kuota ticket OJRS+ yang telah ditentukan.

\section{KEKURANGAN PENERAPAN TICKETING OJRS+}

Akses pada batal tambah OJRS+ terbatas, yaitu 1 (satu) ticket hanya digunakan untuk 1 (satu) kali transaksi. Jumlah ticket dibatasi untuk setiap jamnya, apabila terlalu banyak mahasiswa yang mengakses dan melakukan batal tambah jadwal melalui OJRS+ ini dikhawatirkan akan terjadi error seperti server down atau database error. Belum banyak mahasiswa yang mengetahui tentang fungsi ticketing OJRS+ sehingga tidak dapat melakukan batal tambah mata kuliah dengan maksimal. 


\section{KESIMPULAN}

Dari hasil penelitian ini dapat disimpulkan bahwa penyusunan jadwal kuliah dengan metode generate jadwal ini dapat mengatasi permasalahan seputar penyusunan jadwal kuliah serta dengan sistem batal tambah mata kuliah menggunakan ticketing dapat mengatasi masalah antrian dengan menggunakan pemomoran yang sudah ditentukan tanpa harus melakukan antri tanpa membebani resource banwidth dan server selain itu dikembangkan pula sistem ticketing dengan QR Code sehingga pengguna dapat dengan mudah membaca tiket dengan cara melakukan scan pada $Q R$ Code.

\section{DAFTAR PUSTAKA}

[1] "Journal of technology management \& innovation 7.1 (2012): 17-30.Mendes Lübeck, Rafael, Milton Luiz Wittmann, and Luciana Flores Battistella. "Electronic ticketing system as a process of innovation." Journal of technology management \& innovation 7.1 (2012): 17-30.”

[2] Affani, Fitria. 2013 “Kualitas Pelayanan Kartu Rencana Studi (KRS) Online Di Fakultas Ilmu Sosial dan Ilmu Politik Universitas Sriwijaya” Skripsi. Universitas Sriwijaya

[3] Ainiah. Siti. 2013. "Analisa pengembangan OJRS+Pada Perguruan Tinggi Raharja”. KKP STMIK Raharja: Tangerang.

[4] Aisyah, Euis Sitinur, Dkk. 2015. "Implementasi Sistem Online Jadwal Rencana Studi (OJRS+) pada Perguruan Tinggi Raharja”. Jurnal KNSI. Oktober 2015. Bali : STMIK STIKOM Bali.

[5] Apriyani, Ninu. 2014. "Analisa Sistem OJRS+ Sebagai Media Perencanaan Kuliah Pada Perguruan Tinggi Raharja”. KKP STMIK Raharja : Tangerang.

[6] brahim, Ali. "Pengembangan Sistem Informasi Monitoring Tugas Akhir Berbasis Short Message Service (SMS) Gateway di Fasilkom Unsri." Ogan Ilir: JUSI 1.2 (2011).

[7] Darma, Fakultas Ilmu Komputer Universitas Bina. "Analisa Sistem Informasi Entri KRS Online pada Universitas Bina Darma Dengan Menggunakan Metode END-USER Computing (EUC) Satisfaction." Jurnal Ilmiah Fak. Ilkom Vol 1.1 (2012): 1-20.

[8] Kiong, Tee Poh et al. "Electronic Ticketing in Airline Industries among Malaysians: the Determinants." International Journal of Business and Social Science 5.9 (2014).

[9] Kusmarna, Irfrans, Luh Kesuma Wardhani, and Muhammad Safrizal. "APLIKASI PENJADWALAN MATA KULIAH MENGGUNAKAN ALGORITMA PARTICLE SWARM OPTIMIZATION (PSO)." JURNAL TEKNIK INFORMATIKA 8.2 (2015).

[10] Mönch, Lars et al. "A survey of problems, solution techniques, and future challenges in scheduling semiconductor manufacturing operations." Journal of Scheduling 14.6 (2011): 583-599.

[11] Rahardja Untung, Khanna Tiara, Ray Indra Taufik Wijaya. (2014, Juli). "Penerapan Rinfo Sebagai Media Pendukung Untuk Proses Pembelajaran Pada Perguruan Tinggi Raharja”. Vol. 8 No. 1 ISSN : 1978 - 8282 
[12] Rasdiana, Erlita. 2013. "Analisa pengembangan sistem System Information Student (SIS) pada perguruan tinggi Raharja”. Tangerang : Perguruan Tinggi Raharja.

[13] Song, Zhen et al. "Intelligent scheduling for underground mobile mining equipment." PloS one 10.6 (2015): e0131003.

[14] Suhainingsih, Dwi Maya. 2015. "Penerapan Online Jadwal Rencana Studi Plus Sebagai Media Batal Tambah Penjadwalan Mahasiswa Pada Perguruan Tinggi". Tangerang : Perguruan Tinggi Raharja.

[15] Suhartono, Entot. "OPTIMASI PENJADWALAN MATA KULIAH DENGAN ALGORITMA GENETIKA (Studi Kasus di AMIK JTC Semarang)." INFOKAM 11.5 (2015).

[16] Tryono, Joko. 2010. "Pelayanan KRS Online Berbasis SMS". Jurnal Teknologi, Volume 3 Nomor 1. Institut Sains \& Teknologi AKPRIND: Yogyakarta

[17] Wahyani, Sri. 2015. "Penerapan Online Jadwal Rencana Studi Plus (OJRS+) Untuk Kebutuhan Registrasi Perkuliahan Pada Perguruan Tinggi”. Tangerang : Perguruan Tinggi Raharja

[18] Warsito, Ary Budi, Muhamad Yusup, Iqbal Makaram. 2015. "Perancangan SIS+ Menggunakan Metode YII Framework Pada Perguruan Tinggi Raharja". Jurnal CCIT Vol.8 No.2. Tangerang : Perguruan Tinggi Raharja

[19] Yassein, Muneer Bani, Yaser Khamayseh, and Ali Hatamleh. "A Novel Technique for Jobs Scheduling In Cloud Computing Systems." International Journal of Computer Science and Information Security 14.4 (2016): 562.

[20] Yulianto. 2013. "Pengembangan SiS+ Pada Perguruan Tinggi Raharja Studi Kasus : Daftar Nilai dan Biodata Menggunakan Yii Framework". Skripsi. STMIK Raharja: Tangerang. 